\title{
Retail pharmacy prescription medicines' availability, prices and affordability in Eswatini
}

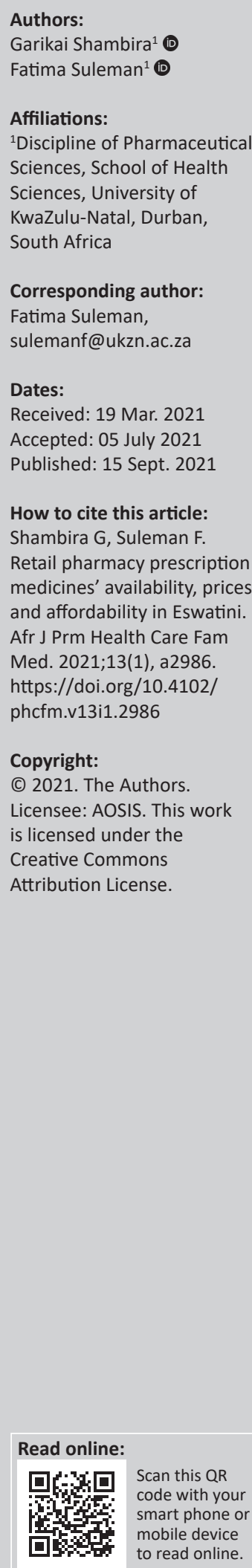

Background: Limited availability of medicines in public facilities and unaffordable prices in the private sector act as barriers to medicines' access. Patients in Eswatini may be forced to buy medicine from the private sector resulting from chronic medicines' shortages in public health facilities. The extent to which they can afford to do so is unknown.

Aim: To determine the availability, price and affordability of medicines in the retail pharmacies in Eswatini, and to compare the results regionally and internationally.

Setting: Retail pharmacy sector in the four administrative regions of Eswatini.

Methods: Data on availability, price and affordability to patients for 50 medicines in the originator brand (OB) and the lowest priced generic (LPG) equivalent, were collated using the standardised World Health Organization/Health Action International methodology from 32 retail pharmacies in the four regions of Eswatini. Prices were then compared with selected countries.

Results: The overall mean availability of all medicines in selected retail pharmacies was 38.5\%; standard deviation [s.d.] $=20.4 \%$ for OBs and $80.9 \%$; s.d. $=19.0 \%$ for LPGs. The overall median price ratio (MPR) in the surveyed pharmacies was 18.61 for the OBs and 4.67 for LPGs. Most standard treatments with LPGs cost less than a day's wages whilst for OBs cost more than a day's wages. The differences between Eswatini and South African prices were statistically significant.

Conclusion: Drug pricing policies and price monitoring tools are needed for the whole pharmaceutical chain in Eswatini to monitor availability, affordability and accessibility of medicines to the general populace.

Keywords: Eswatini; comparison; South Africa; retail medicines' prices; affordability; availability.

\section{Introduction}

Although medicines are crucial in the healthcare system, they are generally not affordable to people globally. It is well documented in literature that prohibitive pricing is one of the major barriers to essential medicines' access. ${ }^{1,2,3}$ There is significant underuse of costly medicines in populations that do not have any medical insurance, and thus, even the smallest price changes in drugs will impact adherence significantly amongst the poor. ${ }^{4}$

More than $30 \%$ of the world population does not have reliable access to essential medicines. ${ }^{5}$ In some of the poorest countries in Asia and Africa, the proportion is as high as $50 \%$. Unavailability and/or low availability of essential medicines in the public health outlets may become a major barrier to medicines' access, especially when coupled with high unaffordable prices in the private sector. ${ }^{6}$ It is thus imperative that prices in the private sector be affordable to ensure equitable access. ${ }^{7,8}$

Medicines' expenditure constitutes between $20 \%$ and $60 \%$ of health expenditure in low- and middle-income nations compared to just $18 \%$ in the European nations. In developing countries, only a mere $10 \%$ have health insurance and the rest buy medication through out-of-pocket payments, which makes medication the biggest family expenditure item after food. ${ }^{9}$

Different policy options are available to governments to regulate pharmaceutical pricing such as free pricing, price-regulated options, price differentiation, price competition and discounts, and tendering procedures. ${ }^{10}$ Different schemes are used globally to regulate drug prices; for example, 


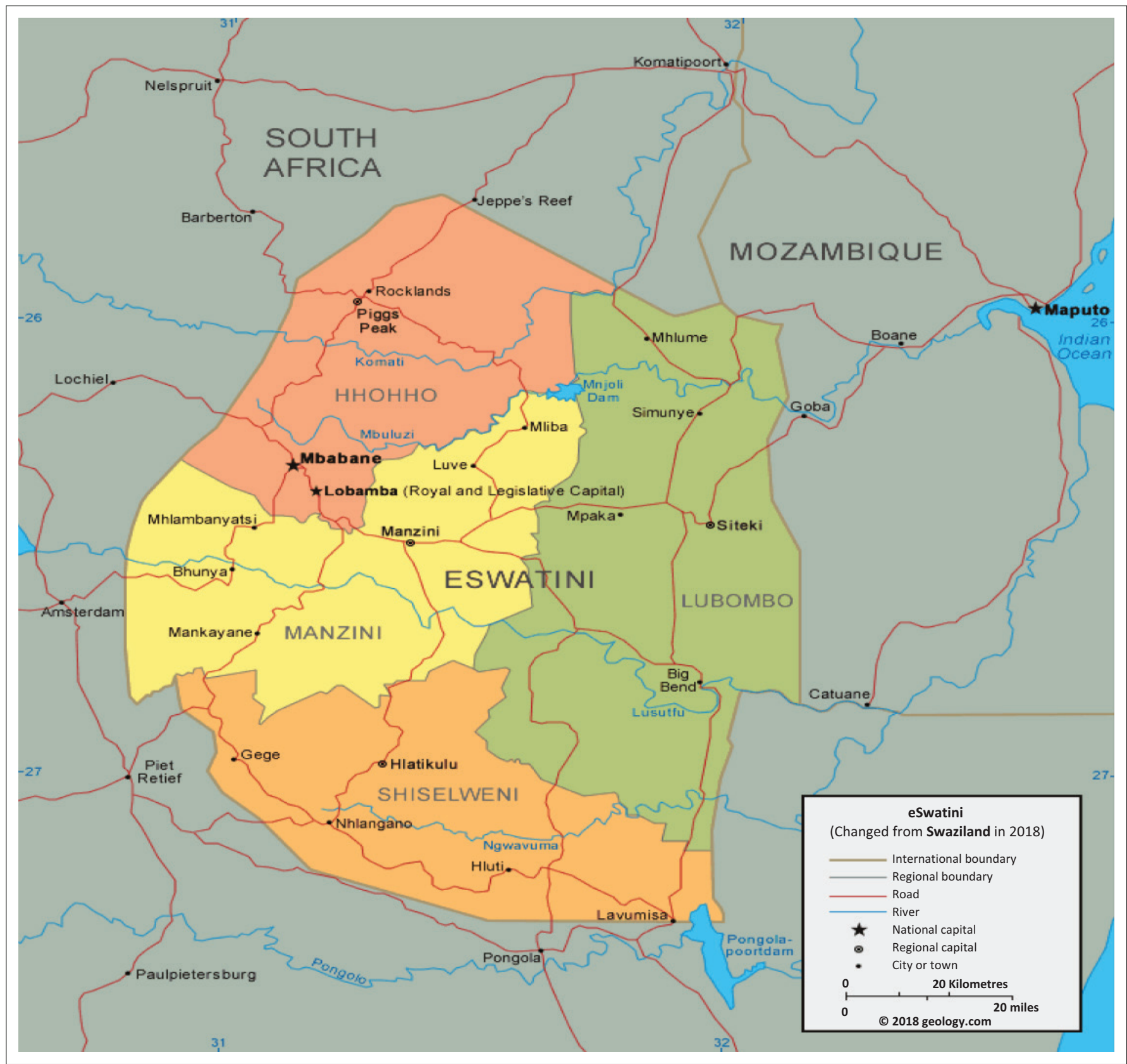

Source: eSwatini (Swaziland) map and satellite image [homepage on the Internet]. Geology.com; n.d. [cited 2021 Aug 16] Available from: https://geology.com/world/swazilandsatellite-image.shtml

FIGURE 1: Eswatini (formerly Swaziland) map.

France and Italy utilise drug price controls to directly manage the drug prices. In Germany and Japan, prices are indirectly controlled via reimbursement under social insurance schemes. The National Pharmaceutical Price Authority in the United Kingdom (UK) monitors price by regulating the profits that companies make on branded prescription medicines' sales. ${ }^{11}$ It is widely believed that the drug prices are generally higher in countries with less stringent price regulation (like the UK) or no regulation at all (the United States [US]) as compared to countries with strict price regulation. ${ }^{12}$

The market share of originator brands (OBs) reduces significantly after the introduction of generics after the expiration of patent protection, and the competition between the generic options lowers the prices of the branded products further. ${ }^{12}$ Free-pricing systems may lower the medicines' prices when optimum conditions are created, and as much as regulation in price-controlled systems may reduce the prices of both generics and brands, it may become a barrier to incentives to lowering prices below the listed ones. ${ }^{10}$

Studies in the US in price variability with other commodities besides pharmaceuticals found that the poorer individuals usually find themselves paying more for similar goods and services as compared to their richer counterparts. ${ }^{13}$ The grocery stores in poorer locations are usually smaller and more expensive than in the wealthier suburbs, mainly because of the existence of large chain stores in the more affluent areas and mainly independents in the poorer 
areas. ${ }^{13,14}$ Not much is known about price regulation or affordability in low- and middle-income countries, especially across the African region.

Eswatini is classified as a lower-middle-income country with the majority of the population living below the upper poverty line. ${ }^{15}$ Although Mhlanga et al. ${ }^{16}$ recommended implementation of a pharmaceutical pricing policy in 2016, there is still no price regulation of pharmaceuticals in Eswatini. ${ }^{17}$ Mhlanga et al. ${ }^{16}$ highlighted the importance of reliable evidence on medicines' prices in ascertaining the type of challenges in a system, before deciding on solutions to ensure availability of essential medicines at the lowest possible price to the consumer.

Prices for prescription medicines are a significant obstacle to appropriate medicine use. ${ }^{18}$ It is not easy to find reliable medicines' prices' information in developing countries, ${ }^{19}$ including Eswatini. The World Health Organization/Health Action International (WHO/HAI) has set a benchmark of $80 \%$ medicine availability as high to ensure the supply of essential medicines. ${ }^{20}$ Although generic medicines are way cheaper than the OBs, they are still relatively unaffordable in many parts of developing countries. ${ }^{21}$

The Medicines Regulatory Unit in the Ministry of Health is currently responsible for medicines' registration; however, a medicines' regulatory authority and pharmacy council are still to be established in Eswatini. ${ }^{22}$ All prescription medicines (defined as any medicine on a valid doctor's prescription) attract value added tax (VAT) at $0 \%$, and where there is no prescription, VAT is levied at $15 \% .{ }^{17}$ Cross-national differences in pharmaceutical prices are of great importance as they help governments to come up with appropriate domestic pricing policies. ${ }^{23}$

South Africa, as Eswatini's neighbour, is considered as an upper-middle-income country and has introduced price controls for medicines. The single exit price (SEP) mechanism lists the price that a medicine can be sold by a manufacturer to an end dispenser. The South African Medicines and Related Substances Act (as amended) regulates the maximum additional dispensing fee that can be charged by people licensed to dispense and retail pharmacists, based on a tier structure directly tied to the SEP. All retail medicines attract a $15 \%$ VAT. ${ }^{24}$ The Act has a provision that prohibits the use of bonuses, rebates or any incentives in the supply of medicines, to avoid undermining the SEP..$^{25}$

The aim of this study was to investigate the availability, affordability and prices that people pay for medicines in different parts of Eswatini. In addition, this study sought to ascertain how the medicines' prices in Eswatini were compared to the prices of the same medicines in South Africa and internationally.

\section{Research methods and design Study design}

A quantitative study using a cross-sectional descriptive design was employed.

\section{Setting}

Eswatini is a very small country, at just over $17000 \mathrm{~km}^{2}$ and a population of just over a million people and a population density of $66.1 \%$ people $/ \mathrm{m}^{2}$. It is located in southern Africa and is bordered by South Africa and Mozambique (see Figure 1). The country is divided into four regions: Hhohho (north-west: $28.5 \%$ of the population), Manzini (central: $30.5 \%$ of the population), Lubombo (east: $21 \%$ of the population) and Shiselweni (south: $20.5 \%$ of the population). ${ }^{27}$

The urban population in Eswatini is $24.2 \%$, and the unemployment rate was estimated at $23.4 \%$ in $2020 .{ }^{27}$ Consultation fee is levied at $\$ 1.41$ in the public sector, and medicines are free. ${ }^{16}$ The lowest paid government worker in Eswatini earns a daily wage of \$8.86 (\$1.00 = Swazi lilangeni [SZL] 17.103 according to the exchange rate as at 15 June 2020)..$^{28}$ Less than $20 \%$ afford medical insurance, and patients in Eswatini may be forced to buy medicines from the private sector because of the chronic medicines' shortages in Eswatini public health facilities. ${ }^{16}$

Pricing surveys have been used to determine the extent of price differentiation and affordability in countries. Thus, for Eswatini, the WHO/HAI medicine price survey was used to identify medicine pricing and affordability in the country in order to provide policymakers and all stakeholders with evidence to draft policies that may improve availability, affordability and accessibility of medicines. ${ }^{6,20}$

\section{Study population and sampling strategy}

A list of pharmacies was obtained from the office of the Deputy Director of Pharmaceutical Services in the Ministry of Health of the 60 registered retail pharmacies in Eswatini at the time of the study, with 14 geographically situated in Hhohho, 30 in Manzini, 10 in Lubombo and six in the Shisweleni region. Stratified sampling was used to group the pharmacies. The primary criterion was the region of location for the pharmacy.

A total number of 32 pharmacies were included in the study. Random disproportionate stratified sampling was used to ensure that the sample was representative of the Eswatini retail pharmacy population. The sample comprised 12 pharmacies from Manzini, eight from Hhohho, six from Lubombo and six from Shiselweni. Simple random sampling was used to select the pharmacies to use in each region. To analyse the effect of the size of the city/town on prescription prices, pharmacies were categorised as from either city or town/rural area. Categorisation of pharmacy size was based on the population of the location:

- City population $\geq 50000$

- Town/rural population $<50000$

\section{Data collection}

The survey included a total of 50 medicines (Appendix Table 1-A1). The list comprised the WHO/HAI Global Core List of 14 medicines and 36 supplementary lists based on the disease burden and local relevance in Eswatini. Expert advice was 
sought from pharmacists, medical doctors, academicians and Ministry of Health Professionals on the relevance of the selected medicines. For analysis, medicines were stratified by use (i.e. anti-infectives [AI] and non-communicable disease [NCD] medicines) and also on whether they were on the essential medicines list (EML) or not.

The managers and/or responsible pharmacists of the selected facilities were contacted via email and telephonically explaining the objectives of the study and the information that would be collected from their pharmacies. The responsible were informed that they were not obliged to participate in the study and that all identity information would be kept confidential.

Data collection took place between 15 June 2020 and 13 August 2020. Data on price, availability and affordability to patient were collected for two products, namely the $\mathrm{OB}$ and the LPG using the standardised WHO/HAI methodology. ${ }^{29}$ The following specific data were collected for 50 essential medicines as per the WHO listing (14 from the Global Core List and 36 selected based on local relevance), ${ }^{30}$ using the WHO/HAI workbook, ${ }^{31}$ during visits to 'retail pharmacies':

- The name of pharmacy, administrative region where located, and whether it was in a city or town/rural area.

- Brand/product name and manufacturer of the LPG found at the site.

- Availability of the OB and the LPG.

- Pack size and price of the pack found for the OB and the LPG.

- Any other comments regarding a given product.

During the retail pharmacy visits, data were recorded on hard copy medicine prices' data collection forms. The data collector made sure the data collection forms were complete and legible before leaving an outlet.

As per the standardised methodology, data collection forms were reviewed every day after completion of the fieldwork to ensure data quality. The data were then entered from the hard copy forms into the electronic survey workbook, and the double-entry programme was run, and any mistakes were corrected. Any questionable data identified after running data checker were investigated and corrected.

\section{Data analysis}

Data were entered in the pre-programmed WHO/HAI Microsoft Excel Workbook. ${ }^{31}$ The workbook automatically generated analysis of the data entered once complete, giving summary tables of percentage availability and median price ratios (MPRs). ${ }^{31}$ Median local prices were expressed as ratios to international reference prices (IRPs), using the formula:

Medicine price median local unit price ratio (MPR) $=\overline{\text { International reference unit price }}$
Management Sciences for Health (MSH)'s 2015 prices were used as the default IRPs. ${ }^{32}$ The IRPs used are prices offered to international not-for-profit agencies for purchase of generics.

The availability of medicines was determined as a percentage of outlets where medicine was found on the day of data collection. Mean availability of the 50 medicines was also reported. The differences in average percentage availability of OBs and LPGs determined if there was any variance in the availability of the two product types. To describe availability, the following ranges were used as reference: ${ }^{19}$

- $<30 \%$ extremely low

- $30 \%-49 \%$ low

- $50 \%-80 \%$ fairly high

- $>80 \%$ high.

The MPR pharmacy prices for each drug were compared across region categories using analysis of variance (ANOVA). The MPR pharmacy prices for each drug were compared between the two categories of location size using $t$-test. The lowest and maximum prices in Eswatini were compared to the lowest and highest permissible retail prices in South Africa (based on current dispensing fee guide in South Africa at the time), ${ }^{33,34}$ and the differences were expressed as percentage price difference for similar products and were analysed using the $t$-test for statistical significance.

Affordability was calculated as the number of wage days that the lowest paid government worker needed to spend to pay for treatment and was based on the median local price of a medicine prescribed at a standard dose. All analysis was carried out using Statistical Package for Social Sciences (SPSS) version 27 (University of KwaZulu-Natal, School of Health Sciences).

\section{Results}

\section{Distribution of pharmacies}

A total number of 32 pharmacies were included in the study. Twelve pharmacies were drawn from Manzini region, eight pharmacies from Hhohho region, six pharmacies from Lubombo region and six pharmacies from Shiselweni region. Of the 32 surveyed pharmacies, 13 of them were located in cities and 19 in towns and rural areas.

\section{Medicines' availability on the day of data collection}

The overall mean availability of all medicines in the surveyed retail pharmacies was 38.5\%; standard deviation [s.d.] = 20.4\% for OBs and 80.9\%; s.d. $=19.0 \%$ for LPGs. Table 1 highlights the mean availability of the different classes of medicines in the different regions.

Although availability data only refer to the day of data collection, the availability of OBs was generally low in all the surveyed pharmacies with only Hhohho region recording more than $50 \%$ availability (56.1\%), whilst 
TABLE 1: Mean availability of selected product groups in the different regions.

\begin{tabular}{|c|c|c|c|c|c|c|}
\hline All & $\begin{array}{c}\text { Mean } \\
\text { availability } \\
\text { Manzini (\%) }\end{array}$ & $\begin{array}{c}\text { Mean } \\
\text { availability } \\
\text { Hhohho } \\
(\%)\end{array}$ & $\begin{array}{c}\text { Mean } \\
\text { availability } \\
\text { Shiselweni } \\
(\%)\end{array}$ & $\begin{array}{c}\text { Mean } \\
\text { availability } \\
\text { Lubombo } \\
(\%)\end{array}$ & $\begin{array}{c}\text { Overall } \\
\text { mean } \\
\text { availability } \\
\text { Eswatini } \\
(\%)\end{array}$ & $N$ \\
\hline LPGs & 83.3 & 82.4 & 79.6 & 76.2 & 80.9 & - \\
\hline OBs & 42.3 & 56.1 & 28.5 & 23.6 & 38.6 & - \\
\hline \multicolumn{7}{|l|}{ Medicine type } \\
\hline Anti-infectives & - & - & - & - & - & 8 \\
\hline LPGs & 85.7 & 87.5 & 88.9 & 71.4 & 86.7 & - \\
\hline OBs & 37.5 & 39.6 & 23.3 & 13.3 & 30.7 & - \\
\hline NCD medicines & - & - & - & - & - & 42 \\
\hline LPGs & 82.9 & 81.1 & 83.3 & 76.4 & 82.3 & - \\
\hline OBs & 41.9 & 21.4 & 29.2 & 21.4 & 38.5 & - \\
\hline \multicolumn{7}{|l|}{$\begin{array}{l}\text { Essential } \\
\text { medicines }\end{array}$} \\
\hline On EML & - & - & - & - & - & 38 \\
\hline LPGs & 86.7 & 88.9 & 84.2 & 80.2 & 85.1 & - \\
\hline OBs & 37.6 & 57.2 & 18.4 & 25.6 & 38.3 & - \\
\hline Not on EML & - & - & - & - & - & 12 \\
\hline LPGs & 72.9 & 69.8 & 65.3 & 62.5 & 69.0 & \\
\hline OBs & 40.2 & 49.0 & 26.7 & 19.4 & 40.0 & \\
\hline \multicolumn{7}{|l|}{ Sample list } \\
\hline Global core & - & - & - & - & - & 14 \\
\hline LPGs & 89.3 & 91.1 & 88.1 & 88.1 & 89.2 & - \\
\hline OBs & 41.7 & 48.8 & 35.0 & 30.0 & 40.0 & - \\
\hline Supplementary & - & - & - & - & - & 36 \\
\hline LPGs & 81.0 & 78.9 & 76.2 & 71.4 & 77.7 & - \\
\hline OBs & 42.6 & 58.8 & 26.2 & 22.0 & 38.0 & - \\
\hline
\end{tabular}

$\mathrm{OB}$, originator brand; $\mathrm{LPG}$, lowest priced generic equivalent; NCDs, non-communicable diseases; EML, essential medicines list.

$n=50$.

Manzini had $42.3 \%$ availability, Shiselweni $28.5 \%$ and then Lubombo with $23.6 \%$ availability. Analysis of variance results showed there were significant differences between the regions in terms of $\mathrm{OB}$ availability $(p<0.001)$. A post hoc test (Bonferroni's correction) showed that Hhohho had significantly higher OB availability than Manzini, Shiselweni and Lubombo regions $(p<0.001)$. The difference between Manzini and Lubombo $(p=0.170)$, Manzini and Shiselweni $(p=1.000)$ and Lubombo and Shiselweni $(p=1.000)$ was not statistically significant.

The mean availability of LPGs was fairly high in Lubombo and Shiselweni and high in Manzini and Hhohho, with the highest availability of $83.3 \%$ recorded in Manzini, followed by $82.4 \%$ in the Hhohho region, then Shiselweni with $79.6 \%$ and lastly Lubombo region with an availability of $76.2 \%$. The differences were not statistically different $(p<0.001)$.

The overall mean availability of OBs in the surveyed outlets varied from $0.0 \%$ for medicines like simvastatin and glibenclamide to $88.5 \%$ for metformin. The higher mean availability of the LPGs was evident with 30 out of the 50 surveyed medicines recording more than $90.0 \%$ availability and six medicines with $100.0 \%$ availability.

Results showed that the pharmacies located within cities had a higher OB mean availability $(x=54.3 \%$, s.d. $=24.6 \%)$ as compared to the outlets situated in towns and rural areas $(x=28.6 \%$, s.d. $=19.4 \%)$. The mean difference $(25.7 \%)$ between the two locations was statistically significant $(p=0.001)$.

The availability of LPGs was high in the city and fairly high in the town located pharmacies, with pharmacies in the cities registering $87.4 \%$ availability and the outlets in towns and rural areas recording $76.5 \%$ availability. Results showed that this difference was statistically significant $(p=0.001)$.

The overall availability of all the different groups analysed was generally high for the LPGs and low for the OBs. The global core medicines had the highest LPG mean availability $(89.2 \%$; s.d. $=9.0 \%)$, followed by $\mathrm{AI}$ at $86.7 \%$, then EML medicines with $85.1 \%$, followed by $82.3 \%$ for the NCD medicines and then $77.7 \%$ overall mean availability for the supplementary medicines (Table 1). The differences between the different regions in terms of availability of LPGs of the different classes were not statistically significant. A similar trend was observed with respect to availability of the different medicines' groups in both cities and smaller towns and the rural areas.

\section{Consolidated private retail sector patient price ratios}

Of the 50 medicines surveyed in the 32 outlets, price ratios were calculated for 33 OBs and 48 LPGs (where medicines were found in four or more outlets). Overall, the MPR was 18.60 for the OBs, whilst the MPR for the LPGs for Eswatini retail outlets was 4.51 . The 25 th and 75 th percentile MPRs for OBs were 3.91 and 36.75, respectively, with an MPR range of 132.58 (0.70-133.28), and for the LPGs, they were 1.98 and 10.36, respectively, with 0.23 as the minimum MPR and 60.72 as the maximum.

\section{Regional patient price comparison}

Overall patient prices in Shiselweni were approximately $4 \%$ and $8 \%$ more than patient prices in Manzini region, whilst the Lubombo prices were approximately $42 \%$ and $9 \%$ more in comparison with Manzini for OBs and LPGs, respectively. The overall MPR patient prices in Shiselweni were approximately $7 \%$ cheaper than the prices in Hhohho for the LPGs. Analysis of variance results showed there was no significant difference between the regions in terms of LPG prices $(p<0.719)$.

A few of the LPGs had large price differentials across the different regions. The LPG omeprazole $20 \mathrm{mg}$ cap/tab was sold to patients at 3.18 MPR in Manzini, but was available at more than four times that price in Lubombo and Shiselweni regions. Comparatively in the Hhohho region, the patients had to part with almost 10 times the Manzini price. The LPG furosemide was available at 2.12 MPR in Manzini, required more than 3 times this in Lubombo and Shiselweni, and was available at 9.38 MPR in the Hhohho region. Atenolol $50 \mathrm{mg}$, diclofenac $50 \mathrm{mg}$ and fluoxetine $20 \mathrm{mg}$ also showed large price differentials across the regions. 
Overall patient prices in the cities were 3\% more and 5\% less than patient prices in the smaller towns for OBs and LPGs, respectively. The LPG diazepam $5 \mathrm{mg}$ was available to patients at $1.12 \mathrm{MPR}$ to patients in the cities, whilst it was sold at 6.58 MPR in the smaller towns.

$\mathrm{OB}$ price ratios were only analysed for Hhohho and Manzini regions as the other two regions did not have significant $O B$ availability for any meaningful comparison. Overall, patient prices in Manzini were approximately 3\% and 1\% more than patient prices in the Hhohho region for OBs and LPGs, respectively. Results showed that the difference between Manzini and Hhohho OB medicines' prices was not statistically significant ( $p=0.166)$.

\section{Comparison of retail prescription drug prices in Eswatini and South Africa}

Of the 32 OBs that were found in more than four outlets in Eswatini only two products, diclofenac $50 \mathrm{mg}$ capsule/tablet (cap/tab) and amlodipine $5 \mathrm{mg}$ cap/tab had their highest prices equal to the maximum permissible South African patient price, whilst eight products had their Eswatini highest prices lower than the maximum permissible South African patient prices, and the rest had Eswatini highest prices that were more than the maximum permissible South African patient prices (see Table 3). The differences were statistically significant $(p=0.004)$. Only one product, carvedilol $12.5 \mathrm{mg}$ cap/tab, had its lowest Eswatini unit price lower than the cheapest South African patient price, whilst the lowest prices for all the other OBs were higher than the lowest prices in South Africa of the same products. The differences were statistically significant $(p=0.14)$.

Of the 48 LPGs analysed, one product, tamsulosin, had its Eswatini lowest price equal to South Africa's lowest generic patient price, 26 products' Eswatini lowest prices were higher than South Africa's lowest prices and 18 products had their lowest prices lower than corresponding South African LPGs for the same molecules. The lowest prices of simvastatin $20 \mathrm{mg}$ and omeprazole $20 \mathrm{mg}$ were more than $300 \%$ lower than the lowest generic patient prices in South Africa. The lowest and highest LPG prices for South Africa were calculated using the MRPs from the Mediscor platform. ${ }^{34}$

Of all the LPGs that were analysed, only 11 products had Eswatini highest prices lower than the South African maximum permissible patient prices in the retail pharmacies. The other 37 products had highest prices, higher than the highest generic patient prices for similar molecules in South Africa. The difference in the prices was statistically significant $(p=0.014)$.

\section{Treatment affordability}

The LPGs for the most common AI were generally affordable in all the regions, with an adult 7 days' course of amoxicillin, a paediatric 7 days' course of co-trimoxazole and a paediatric 7 days' course of amoxicillin + clavulanic acid, all requiring less than a day's wages of the lowest paid government unskilled worker to purchase them (see Table 4). The OB for amoxicillin and clavulanic acid, however, required 2.28 days' wages in Manzini and 2.13 days' wages in the Hhohho region. A single dose of $1 \mathrm{~g}$ azithromycin for the treatment of chlamydial infections was unaffordable for both LPGs and OBs in all the regions, save for Shiselweni region where purchasing the LPG course required only 0.94 days' wages of the lowest paid unskilled government worker.

A standard 1-month treatment course for benign prostate hypertrophy $(\mathrm{BPH})$ with tamsulosin $0.4 \mathrm{mg}$ once daily was unaffordable in all the four regions for both the LPGs and OBs. The lowest paid unskilled government worker needed to work for 3 days to afford the LPG and 5.98 days to be able to buy the $\mathrm{OB}$ in Manzini region.

Management of depression with fluoxetine $20 \mathrm{mg}$ once daily was affordable for the LPGs in all the regions requiring 0.56 days' worth of wages of the lowest paid government unskilled worker Manzini, 0.88 days' wages in Shiselweni, 0.95 days' wages in Lubombo and 0.96 days' wages in the Hhohho region (Table 2). The OB was only available in Hhohho and required the lowest paid unskilled government employee to work 7.16 days to afford to purchase a course for 1 month.

The first-line LPG anti-hypertensives (hydrochlorothiazide, captopril and atenolol) were affordable in all the four regions of Eswatini requiring less than a day's wage to purchase a course, with hydrochlorothiazide being the most affordable, requiring only under 0.25 day's wages of the lowest paid unskilled government employee to purchase it. The secondline and third-line anti-hypertensives were generally unaffordable, requiring more than a day's wages for both the OBs and LPGs, apart from the LPGs for $20 \mathrm{mg}$ enalapril in Manzini (0.86 days) and Shiselweni (0.66 days).

The three anti-epileptic medicines surveyed required more than a day's wages to buy a course for 1 month, save for the LPGs for phenytoin $100 \mathrm{mg}$ tablets which required 0.94 days' wages in Manzini and 0.95 days' wages in the Hhohho region. To afford a course of sodium valproate for a month, the lowest paid government worker had to work for 4.52 days for the $\mathrm{OB}$ and 3.55 days for the LPG. A similar trend was observed with carbamazepine as well, with the most affordable OB requiring 4.19 days' wages, whilst the most affordable LPG required 2.38 days' wages to purchase a course.

A course of salbutamol inhaler required less than 0.2 day's wages for the LPGs and just under 0.5 days' wages for the $\mathrm{OB}$ in all the regions where stock was available. Less than a single day's wages were adequate to purchase a month's supply of the LPGs of beclomethasone $100 \mathrm{mg}$ inhaler in all the regions surveyed. Management of asthma with montelukast $5 \mathrm{mg}$ once daily was unaffordable for both LPGs and OBs (requiring more than 3 days' wages for the LPGs and just under 8 days' wages for the OBs), as was fluticasone/ salmeterol $25 / 250$ mcg which required about 6 days' wages for the LPGs and more than 10 days' wages to purchase a monthly course of the OBs. 
TABLE 2: Eswatini median price ratio comparison by location.

\begin{tabular}{|c|c|c|c|c|c|c|}
\hline \multirow[t]{2}{*}{ Medicine name (LPG) } & \multicolumn{6}{|c|}{ Median price ratio (MPR) } \\
\hline & $\begin{array}{l}\text { Manzini } \\
(n=12)\end{array}$ & $\begin{array}{l}\text { Hhohho } \\
(n=8)\end{array}$ & $\begin{array}{l}\text { Shiselweni } \\
\quad(n=6)\end{array}$ & $\begin{array}{l}\text { Lubombo } \\
(n=5)\end{array}$ & $\begin{array}{l}\text { Town/ } \\
\text { rural } \\
(n=19)\end{array}$ & $\begin{array}{c}\text { City } \\
(n=13)\end{array}$ \\
\hline $\begin{array}{l}\text { Acyclovir } 200 \text { mg cap/ } \\
\text { tab }\end{array}$ & 5.79 & 5.66 & 5.33 & 5.02 & 5.53 & 5.6 \\
\hline $\begin{array}{l}\text { Amitriptyline } 25 \text { mg } \\
\text { cap/tab }\end{array}$ & 9.98 & 11.07 & 9.27 & 12.47 & 10.00 & 10.79 \\
\hline $\begin{array}{l}\text { Amlodipine } 5 \mathrm{mg} \text { cap/ } \\
\text { tab }\end{array}$ & 11.68 & 11.68 & 10.29 & 13.99 & 11.69 & 11.67 \\
\hline $\begin{array}{l}\text { Amoxicillin } 500 \text { mg cap/ } \\
\text { tab }\end{array}$ & 2.26 & 2.10 & 2.63 & 2.58 & 2.49 & 2.01 \\
\hline $\begin{array}{l}\text { Amoxicillin + clavulanic } \\
\text { acid } 125 \mathrm{mg}+31.25 \mathrm{mg} \\
\text { susp }\end{array}$ & 0.23 & 0.21 & 0.20 & 0.30 & 0.26 & 0.22 \\
\hline $\begin{array}{l}\text { Anhydrous theophylline } \\
200 \mathrm{mg} \text { cap/tab }\end{array}$ & 3.85 & - & 3.19 & 3.73 & 3.63 & 3.85 \\
\hline Atenolol $50 \mathrm{mg}$ cap/tab & 8.00 & 6.71 & 12.08 & 4.20 & 7.88 & 8.11 \\
\hline $\begin{array}{l}\text { Atorvastatin } 20 \mathrm{mg} \text { cap/ } \\
\text { tab }\end{array}$ & 0.97 & 0.92 & 0.99 & 1.37 & 1.09 & 0.87 \\
\hline $\begin{array}{l}\text { Azithromycin } 500 \text { mg } \\
\text { cap/tab }\end{array}$ & 13.00 & 14.52 & 10.13 & 15.59 & 13.3 & 14.22 \\
\hline $\begin{array}{l}\text { Beclomethasone } \\
100 \mathrm{mcg} / \text { dose } \mathrm{Inh}\end{array}$ & 1.63 & 1.55 & 1.51 & 1.55 & 1.5 & 1.59 \\
\hline Bisoprolol $5 \mathrm{mg}$ cap/tab & 1.55 & 1.78 & 1.54 & 2.01 & 1.67 & 1.57 \\
\hline $\begin{array}{l}\text { Budesonide } 0.5 \mathrm{mg} / \mathrm{mL} \\
\text { Neb susp }\end{array}$ & 59.44 & 62.40 & - & - & 61.27 & 60.72 \\
\hline Captopril 25 mg cap/tab & 1.27 & 1.10 & 1.46 & 1.56 & 1.46 & 1.22 \\
\hline $\begin{array}{l}\text { Carbamazepine } 200 \text { mg } \\
\text { cap/tab }\end{array}$ & 10.48 & 10.95 & 10.68 & 11.92 & 11.1 & 10.71 \\
\hline $\begin{array}{l}\text { Carvedilol } 12.5 \mathrm{mg} \\
\text { cap/tab }\end{array}$ & 1.31 & 1.31 & 1.31 & 1.43 & 1.32 & 1.31 \\
\hline $\begin{array}{l}\text { Ceftriaxone injection } \\
1 \mathrm{~g} / \text { vial }\end{array}$ & 6.49 & 5.78 & 8.17 & 8.17 & 8.17 & 5.77 \\
\hline Cetirizine $10 \mathrm{mg}$ cap/tab & 14.77 & 16.97 & 14.98 & 17.75 & 16.62 & 15.06 \\
\hline $\begin{array}{l}\text { Ciprofloxacin } 500 \text { mg } \\
\text { cap/tab }\end{array}$ & 6.51 & 6.89 & 7.47 & 7.85 & 7.46 & 6.7 \\
\hline $\begin{array}{l}\text { Co-trimoxazole } \\
\text { suspension } 8 \mathrm{mg}+ \\
40 \mathrm{mg} / 5 \mathrm{~mL} \text { susp }\end{array}$ & 2.12 & 1.90 & 2.36 & 2.39 & 2.3 & 1.87 \\
\hline Diazepam 5 mg cap/tab & 2.22 & 1.00 & - & - & 6.58 & 1.12 \\
\hline $\begin{array}{l}\text { Diclofenac } 50 \text { mg cap/ } \\
\text { tab }\end{array}$ & 6.51 & 7.09 & 9.57 & 9.57 & 9.57 & 6.64 \\
\hline Enalapril $20 \mathrm{mg}$ cap/tab & 12.30 & 14.55 & 9.45 & 16.96 & 12.33 & 12.54 \\
\hline $\begin{array}{l}\text { Fluoxetine } 20 \mathrm{mg} \text { cap/ } \\
\text { tab }\end{array}$ & 2.12 & 3.63 & 3.33 & 3.58 & 3.41 & 3.27 \\
\hline $\begin{array}{l}\text { Fluticasone/salmeterol } \\
25 / 250 \mathrm{mg} \operatorname{lnh}\end{array}$ & 10.16 & 11.01 & - & 10.80 & 10.8 & 11.01 \\
\hline $\begin{array}{l}\text { Furosemide } 40 \mathrm{mg} \text { cap/ } \\
\text { tab }\end{array}$ & 2.12 & 9.38 & 6.59 & 7.69 & 6.59 & 4.33 \\
\hline $\begin{array}{l}\text { Glibenclamide } 5 \text { mg } \\
\text { cap/tab }\end{array}$ & 4.69 & 4.60 & 4.14 & 6.05 & 4.47 & 4.47 \\
\hline $\begin{array}{l}\text { Gliclazide } 80 \text { mg cap/ } \\
\text { tab }\end{array}$ & 1.84 & 1.90 & 1.76 & 1.77 & 1.76 & 2.01 \\
\hline $\begin{array}{l}\text { Hydrochlorothiazide } \\
25 \mathrm{mg} \text { cap/tab }\end{array}$ & 6.56 & 9.05 & 8.04 & 8.74 & 8.74 & 6.4 \\
\hline $\begin{array}{l}\text { Hydrochlorothiazide/ } \\
\text { losartan } 12.5 / 50 \mathrm{mg} \\
\text { cap/tab }\end{array}$ & 1.78 & 1.79 & - & - & 1.6 & 1.79 \\
\hline $\begin{array}{l}\text { Irbesartan } 150 \text { mg cap/ } \\
\text { tab }\end{array}$ & 10.40 & 10.61 & 9.92 & 11.04 & 10.83 & 10.21 \\
\hline $\begin{array}{l}\text { Loratadine } 10 \mathrm{mg} \text { cap/ } \\
\text { tab }\end{array}$ & 6.20 & 7.13 & 5.97 & 6.53 & 6.15 & 7.09 \\
\hline Losartan 10 mg cap/tab & 1.93 & 2.13 & 1.72 & 2.22 & 1.92 & 2.07 \\
\hline $\begin{array}{l}\text { Metformin } 500 \mathrm{mg} \mathrm{cap} / \\
\text { tab }\end{array}$ & 2.55 & 2.41 & 2.25 & 2.22 & 2.39 & 2.34 \\
\hline $\begin{array}{l}\text { Methyldopa } 250 \text { mg } \\
\text { cap/tab }\end{array}$ & 2.57 & 2.65 & 2.39 & 2.66 & 2.66 & 2.47 \\
\hline $\begin{array}{l}\text { Montelukast } 5 \mathrm{mg} \text { cap/ } \\
\text { tab }\end{array}$ & 6.61 & 7.07 & 7.14 & 7.25 & 7.14 & 7.03 \\
\hline $\begin{array}{l}\text { Nifedipine retard } 20 \mathrm{mg} \\
\text { cap/tab }\end{array}$ & 4.80 & 4.64 & 4.41 & 5.19 & 4.55 & 4.57 \\
\hline $\begin{array}{l}\text { Omeprazole } 20 \text { mg cap/ } \\
\text { tab }\end{array}$ & 3.18 & 31.48 & 14.26 & 14.26 & 14.26 & 20.45 \\
\hline
\end{tabular}

TABLE 2 (Continues...): Eswatini median price ratio comparison by location. Medicine name (LPG) Median price ratio (MPR)

\begin{tabular}{|c|c|c|c|c|c|c|}
\hline & $\begin{array}{l}\text { Manzini } \\
(n=12)\end{array}$ & $\begin{array}{l}\text { Hhohho } \\
(n=8)\end{array}$ & $\begin{array}{l}\text { Shiselweni } \\
\quad(n=6)\end{array}$ & $\begin{array}{l}\text { Lubombo } \\
\qquad(n=5)\end{array}$ & $\begin{array}{c}\text { Town/ } \\
\text { rural } \\
(n=19)\end{array}$ & $\begin{array}{l}\text { City } \\
(n=13)\end{array}$ \\
\hline $\begin{array}{l}\text { Paracetamol suspension } \\
24 \mathrm{mg} / \mathrm{mL} \text { susp }\end{array}$ & 1.67 & 1.69 & 2.04 & 2.21 & 2.05 & 1.68 \\
\hline $\begin{array}{l}\text { Phenytoin } 100 \text { mg cap/ } \\
\text { tab }\end{array}$ & 4.94 & 4.99 & 5.20 & 5.84 & 5.52 & 4.98 \\
\hline $\begin{array}{l}\text { Propranolol } 40 \text { mg cap/ } \\
\text { tab }\end{array}$ & 3.57 & 3.02 & 3.45 & 4.16 & 3.83 & 3.42 \\
\hline $\begin{array}{l}\text { Risperidone } 2 \mathrm{mg} \\
\text { cap/tab }\end{array}$ & 57.91 & 62.09 & 50.40 & - & 54.41 & 60.59 \\
\hline $\begin{array}{l}\text { Salbutamol inhaler } \\
100 \mathrm{mcg} / \text { dose }\end{array}$ & 1.57 & 1.58 & 1.35 & 1.65 & 1.46 & 1.55 \\
\hline $\begin{array}{l}\text { Salbutamol syrup } \\
2 \mathrm{mg} / 5 \mathrm{~mL}\end{array}$ & 2.40 & 2.55 & 2.46 & 2.63 & 2.58 & 2.51 \\
\hline $\begin{array}{l}\text { Simvastatin } 20 \text { mg cap/ } \\
\text { tab }\end{array}$ & 1.79 & 1.86 & 1.58 & 1.70 & 1.68 & 1.86 \\
\hline $\begin{array}{l}\text { Sodium valproate } \\
200 \mathrm{mg} \text { cap/tab }\end{array}$ & 3.67 & 4.16 & 3.67 & 3.37 & 3.55 & 4.08 \\
\hline $\begin{array}{l}\text { Spironolactone } 25 \text { mg } \\
\text { cap/tab }\end{array}$ & 3.06 & 3.22 & 2.84 & 2.98 & 2.98 & 3.11 \\
\hline $\begin{array}{l}\text { Tamsulosin } 0.4 \text { mg cap/ } \\
\text { tab }\end{array}$ & 10.60 & 11.13 & 10.72 & 10.81 & 10.76 & 10.72 \\
\hline
\end{tabular}

$\mathrm{mg}$, milligrams per dosage form; cap/tab, capsules or tablets as a dosage form; $\mathrm{mcg} / \mathrm{dose}$, micrograms per dose of medicine; Inh, inhaler; Neb susp, Nebulising suspension; LPG, lowest price generic.

The first line of management for diabetes mellitus 2 (DM II) was affordable for both the OBs and LPGs in all the four regions of Eswatini, with a monthly course of 60 tablets of glibenclamide $5 \mathrm{mg}$ requiring less than 0.5 days' wages to purchase. It is worth noting that less than 0.8 days' wages were required to purchase a course of either the OBs or the LPGs of metformin $500 \mathrm{mg}$ in the four regions. Gliclazide was less affordable and required more than the equivalent of the lowest paid unskilled government worker's single day wage to purchase a course for 1 month of the LPGs. No LPG was found for human insulin (30\% regular $/ 70 \%$ isophane) in all the surveyed areas and the OB required 5.20 days' wages in Manzini, 5.36 days' wages in Hhohho and 7.37 days' wages in the Lubombo region.

Table 5 illustrates the affordability of a 3-drug regimen when OBs and LPGs when purchased from the retail pharmacy sector in Eswatini. The lowest paid government worker would have to work 2 days to afford the LPG regimen, and in case the LPGs are not available, she/he will have to work for 4.8 days to be able to afford the OBs.

\section{Discussion}

The study showed that the overall availability of the LPG medicines in all the regions was higher than the recommended minimum availability benchmark of $80 \%{ }^{20}$ set by WHO/ HAI. It can be deduced from the results that there is promotion of generics' dispensing as compared to the branded products in all the regions. The more affluent settlements are in Hhohho and Manzini regions, and the availability of OBs was comparably higher in these two regions. Guan et al.'s ${ }^{35}$ findings highlighted the challenges associated with regional disparity of essential medicines. Another study looked at the undiscounted prices for both $\mathrm{OB}$ and the LPG for 25 essential medicines from 17 private pharmacies in Shaanxi Province, western China. It noted that 
TABLE 3: Comparison of Eswatini and South Africa's highest and lowest originator brand prescription prices in Emalangeni (E).

\begin{tabular}{|c|c|c|c|c|c|c|}
\hline Medicine name & $\begin{array}{l}\text { Eswatini highest } \\
\text { unit price (E) }\end{array}$ & $\begin{array}{l}\text { S.A. maximum } \\
\text { permissible unit } \\
\text { price (E) }\end{array}$ & $\begin{array}{l}\text { Price difference (\%) } \\
\text { Eswatini relative to S.A. }\end{array}$ & $\begin{array}{l}\text { Lowest unit price - } \\
\text { Eswatini (E) }\end{array}$ & $\begin{array}{l}\text { S.A. lowest unit } \\
\text { price (E) }\end{array}$ & $\%$ price difference \\
\hline Salbutamol inhaler $100 \mathrm{mcg} /$ dose & 1.91 & 0.72 & +62 & 0.51 & 0.41 & +20 \\
\hline Sodium valproate $200 \mathrm{mg}$ cap/tab & 13.27 & 6.45 & +51 & 5.72 & 4.69 & +18 \\
\hline $\begin{array}{l}\text { Hydrochlorothiazide/losartan } 12.5 / 50 \mathrm{mg} \\
\text { cap/tab }\end{array}$ & 14.68 & 7.80 & +47 & 6.09 & 4.85 & +20 \\
\hline $\begin{array}{l}\text { Human insulin 30/70 isophane } 100 \mathrm{iu} / \mathrm{mL} \\
\text { vial }\end{array}$ & 77.14 & 49.25 & +36 & 41.11 & 33.88 & +18 \\
\hline Risperidone $2 \mathrm{mg}$ cap/tab & 55.40 & 35.44 & +36 & 35.94 & 27.52 & +23 \\
\hline Carbamazepine $200 \mathrm{mg}$ cap/tab & 9.67 & 6.98 & +28 & 6.66 & 4.58 & +31 \\
\hline Bisoprolol 5 mg cap/tab & 9.29 & 7.18 & +23 & 5.12 & 4.40 & +14 \\
\hline Fluticasone/salmeterol $25 / 250 \mathrm{mg}$ Inh & 17.51 & 15.27 & +13 & 14.55 & 11.67 & +20 \\
\hline Montelukast $5 \mathrm{mg}$ cap/tab & 25.99 & 23.06 & +11 & 19.86 & 16.78 & +16 \\
\hline Omeprazole 20 mg cap/tab & 36.37 & 32.77 & +10 & 31.24 & 25.05 & +20 \\
\hline Fluoxetine $20 \mathrm{mg} \mathrm{cap} / \mathrm{tab}$ & 21.73 & 19.61 & +10 & 17.53 & 14.02 & +20 \\
\hline Metformin $500 \mathrm{mg}$ cap/tab & 1.49 & 1.36 & +9 & 0.86 & 0.70 & +19 \\
\hline Spironolactone $25 \mathrm{mg}$ cap/tab & 2.84 & 2.63 & +7 & 1.84 & 1.52 & +17 \\
\hline Tamsulosin $0.4 \mathrm{mg}$ cap/tab & 18.78 & 17.38 & +7 & 14.01 & 12.12 & +13 \\
\hline Atorvastatin $20 \mathrm{mg}$ cap/tab & 21.20 & 19.77 & +7 & 15.25 & 14.15 & +7 \\
\hline Irbesartan 150 mg cap/tab & 18.47 & 17.51 & +5 & 12.55 & 11.92 & +5 \\
\hline Ciprofloxacin 500 mg cap/tab & 33.00 & 32.41 & +2 & 24.73 & 21.07 & +15 \\
\hline Losartan $10 \mathrm{mg}$ cap/tab & 7.11 & 7.02 & +1 & 5.02 & 4.28 & +15 \\
\hline Budesonide $0.5 \mathrm{mg} / \mathrm{mL}$ Neb susp & 28.77 & 28.48 & +1 & 24.63 & 20.23 & +18 \\
\hline Enalapril $20 \mathrm{mg}$ cap/tab & 6.78 & 6.72 & +1 & 4.87 & 3.97 & +18 \\
\hline Diclofenac $50 \mathrm{mg}$ cap/tab & 6.06 & 6.04 & 0 & 4.08 & 3.35 & +18 \\
\hline Amlodipine $5 \mathrm{mg}$ cap/tab & 11.28 & 11.30 & 0 & 9.25 & 7.38 & +20 \\
\hline Furosemide $40 \mathrm{mg}$ cap/tab & 9.03 & 9.16 & -1 & 6.65 & 4.87 & +27 \\
\hline Azithromycin 500 mg cap/tab & 107.29 & 109.53 & -2 & 85.58 & 71.32 & +17 \\
\hline Atenolol $50 \mathrm{mg}$ cap/tab & 13.21 & 13.53 & -2 & 11.25 & 9.00 & +20 \\
\hline Nifedipine retard $20 \mathrm{mg}$ cap/tab & 14.82 & 15.54 & -5 & 14.28 & 11.90 & +17 \\
\hline $\begin{array}{l}\text { Amoxicillin + clavulanic acid } 125 \mathrm{mg}+ \\
31.25 \mathrm{mg} \text { susp }\end{array}$ & 2.05 & 2.38 & -16 & 1.66 & 1.48 & +11 \\
\hline Cetirizine $10 \mathrm{mg}$ cap/tab & 9.19 & 10.80 & -18 & 8.59 & 7.02 & +18 \\
\hline
\end{tabular}

Note: $\$ 1.00$ is equivalent to 14.79 Swazi lilangeni (SZL).

$\mathrm{mg}$, milligrams per dosage form; cap/tab, capsules or tablets as a dosage form; mcg/dose, micrograms per dose of medicine; S.A., South Africa; Inh, inhaler; iu, international unit; E, Emalangeni; Neb susp, Nebulising suspension.

generics were more available as compared to OBs and prices varied across different discount programmes. The study concluded that price transparency of pharmaceuticals helps consumers in the identification of potential savings. ${ }^{36}$

The overall availability of LPGs was not different in all the regions. However, the pharmacies located in cities had higher availability than the ones in smaller towns and rural areas for both LPGs and OBs. A survey conducted in Peru using the WHO/HAI medicines' prices and availability survey did not find any significant differences in overall availability or prices of the medicines under study by retail location. ${ }^{15}$ It is commendable that the availability of LPGs on the EML was more than $90 \%$ in all regions, and as such in the event of medicines being unavailable at government hospitals, patients can access medications at retail pharmacies.

It was quite interesting to note that the LPGs' prices were comparable in all the four regions and the differences reflected were not statistically significant. Although there is currently no price regulation administered by the government, ${ }^{37}$ the market forces 'regulate' the medicines' prices in the Eswatini pharmaceutical market. Studies on medicines' prices, availability and affordability carried out in Nairobi County in $2016^{38}$ and in Sudan from March 2012 to April 2013 noted considerable price differences amongst the different regions despite having people of similar social standing. ${ }^{22}$

A careful analysis of the molecules that had large differentials, for example, omeprazole $20 \mathrm{mg}$, showed that the overseas parallel generic imports were available at a significantly lower price to the patients as compared to similar generic molecules that were sourced regionally. The clients in the more affluent locations are generally brand-sensitive as compared to patients in the rural settings, where outlets can afford to keep the most affordable non-branded import generics. There is a need for the authorities to ascertain that these lowly priced molecules also meet the stipulated quality standards.

The study showed that generally the OB patient prices were higher in Eswatini when compared to prices of the same prescription molecules in South Africa, and this is not a deviation from the expected as literature suggests medicines' prices in regulated environments are generally lower than in countries with no price regulation. ${ }^{23}$ Eswatini procures their 
TABLE 4: Affordability of selected lowest price generic medicines.

\begin{tabular}{|c|c|c|c|c|}
\hline \multirow[t]{2}{*}{ Medicine } & \multicolumn{4}{|c|}{$\begin{array}{c}\text { Number of days' wages needed to purchase a } \\
\text { course of treatment }\end{array}$} \\
\hline & Manzini & Hhohho & Shiselweni & Lubombo \\
\hline Amoxicillin $500 \mathrm{mg}$ cap/tab & 0.29 & 0.27 & 0.34 & 0.33 \\
\hline Azithromycin 500 mg cap/tab & 1.20 & 1.35 & 0.94 & 1.45 \\
\hline $\begin{array}{l}\text { Beclomethasone } 100 \mathrm{mcg} / \text { dose } \\
\text { Inh }\end{array}$ & 0.84 & 0.80 & 0.78 & 0.80 \\
\hline Carbamazepine $200 \mathrm{mg}$ cap/tab & 2.38 & 2.48 & 2.42 & 2.70 \\
\hline Enalapril 20 mg cap/tab & 0.86 & 1.02 & 0.66 & 1.19 \\
\hline Fluoxetine 20 mg cap/tab & 0.56 & 0.96 & 0.88 & 0.95 \\
\hline $\begin{array}{l}\text { Fluticasone/salmeterol } 25 / 250 \\
\mathrm{mg} / \text { dose Inh }\end{array}$ & 5.94 & 6.44 & - & 6.32 \\
\hline Glibenclamide 5 mg cap/tab & 0.33 & 0.32 & 0.29 & 0.42 \\
\hline Gliclazide 80 mg cap/tab & 1.10 & 1.14 & 1.05 & 1.06 \\
\hline Human insulin $100 \mathrm{iu} / \mathrm{mL}$ Inj & 5.20 & 5.36 & - & 7.37 \\
\hline $\begin{array}{l}\text { Hydrochlorothiazide } 25 \mathrm{mg} \text { cap/ } \\
\text { tab }\end{array}$ & 0.17 & 0.24 & 0.21 & 0.23 \\
\hline Irbesartan 150 mg cap/tab & 1.89 & 1.93 & 1.80 & 2.00 \\
\hline Losartan 50 mg cap/tab & 1.36 & 1.50 & 1.22 & 1.57 \\
\hline Metformin 500 mg cap/tab & 0.47 & 0.44 & 0.41 & 0.41 \\
\hline Methyldopa $500 \mathrm{mg} \mathrm{cap} / \mathrm{tab}$ & 1.53 & 1.58 & 1.42 & 1.59 \\
\hline Montelukast $5 \mathrm{mg}$ cap/tab & 3.40 & 3.63 & 3.67 & 3.73 \\
\hline Nifedipine SR 20 mg cap/tab & 1.20 & 1.16 & 1.10 & 1.29 \\
\hline Omeprazole 20 mg cap/tab & 0.74 & 2.72 & 1.23 & 1.23 \\
\hline Salbutamol $100 \mathrm{mcg} /$ dose Inh & 0.18 & 0.18 & 0.16 & 0.19 \\
\hline $\begin{array}{l}\text { Sodium valproate } 200 \mathrm{mg} \text { cap/ } \\
\text { tab }\end{array}$ & 3.13 & 3.55 & 3.13 & 2.87 \\
\hline Tamsulosin 0.4 mg cap/tab & 2.93 & 3.08 & 2.97 & 2.99 \\
\hline
\end{tabular}

$\mathrm{mg}$, milligrams per dosage form; cap/tab, capsules or tablets as a dosage form; $\mathrm{mcg} /$ dose micrograms per dose of medicine; Inh, inhaler; iu, international units; SR, sustained release.

TABLE 5: Affordability of treatments for a family with multiple conditions (consolidated retail pharmacy sector-Eswatini).

\begin{tabular}{llccc}
\hline Condition & Treatment & Type & $\begin{array}{c}\text { Median } \\
\text { treatment price } \\
\text { (emalangeni) }\end{array}$ & Days' wages \\
\hline Hypertension & Enalapril $20 \mathrm{mg}$ od $\times$ & LPG & 74.66 & 0.9 \\
& 30 days & OB & 164.93 & 1.9 \\
Diabetes mellitus II & Metformin $500 \mathrm{mg}$ & LPG & 36.60 & 0.4 \\
& twice daily $\times 30$ days & OB & 60.47 & 0.7 \\
Respiratory & Amoxicillin + clavulanic & LPG & 60.40 & 0.7 \\
infection (child) & acid $125 / 31.25 \mathrm{mg}$ & OB & 187.58 & 2.2 \\
\hline Total & 3 times daily $\times 7$ days & OPG & $\mathbf{1 7 1 . 6 6}$ & $\mathbf{2 . 0}$ \\
& - & OB & $\mathbf{4 1 2 . 9 8}$ & $\mathbf{4 . 8}$ \\
\hline
\end{tabular}

$\mathrm{OB}$, originator brand; LPG, lowest priced generic equivalent; Od, once a day.

OBs from South Africa where pricing is regulated, and as such, the best/lowest cost to the retail outlets for these would be at the SEP price and as such it is expected that the retailing prices will be higher than SEP in the Eswatini outlets. Eswatini prescription medicines' prices have VAT at $0 \%$, whereas in South Africa all medicines attract VAT at $15 \%$. If the VAT regulation in Eswatini would change from $0 \%$ to the standard 15\%, ${ }^{24}$ the Eswatini prescription medicines will become more expensive to the end users.

The Eswatini market is not limited to the South African generic molecules only as they also have access to parallel import generics from overseas which were found to be generally cheaper than the South African equivalent molecules. The difference in the gross domestic product (GDP) per capita per month between South Africa and Eswatini needs to be considered, ${ }^{8}$ as a small price difference may turn out to be huge with respect to affordability in the Eswatini context.

Most first-line treatment regimens for NCDs were generally affordable, requiring less than a day's wages. It is worth noting that more than $60 \%$ of Eswatini's population lives below the upper poverty line of $\$ 8.21$ per capita per month, and as such, ${ }^{8}$ treatment regimens calculated as affordable may still be way out of the range for the general populace. ${ }^{16}$ There is usually more than one family member requiring chronic medications, and even though the individual courses may be affordable, the combined regimens will be unaffordable. Anti-epileptic medications and most second-line management regimes required more than a day's wages; hence, unavailability at the public hospitals could lead to patients defaulting their treatments.

\section{Limitations}

Affordability was calculated based on the daily wage of the lowest paid unskilled government worker, but a large portion of the labour force is not employed by the government and the minimum wages are way lower than the salary of the lowest paid government worker, thus the data may not be a true reflection of affordability in Eswatini.

Availability refers to the day of data collection at each facility and might not be indicative of average availability over time. Availability and prices' data were collected during level 2 lockdown (as a result of the [coronavirus disease 2019] COVID-19 pandemic) when supply chains were disrupted, and hence, these findings may not be a true reflection of the availability throughout the year (Eswatini depends entirely on imports as there is no manufacturing of any pharmaceuticals that takes place in the kingdom).

\section{Recommendations}

Future research should focus on comprehensive national surveys in all public and private entities to determine medicines' prices, including from the wholesalers. Price components throughout the entire pharmaceutical supply chain should be studied. Focus on these will assist in developing policies that will work towards improving affordability and availability.

\section{Conclusion}

Drug pricing control by the government is one of the factors responsible for lower retail prices in South Africa. The concept of 'free market economy' in Eswatini may not be enough to regulate the prices of medicines. There is a need to develop drug pricing policies that govern the whole supply chain. ${ }^{16}$ However, for that to happen all the necessary data on the current pricing structure in the whole pharmaceutical supply chain of Eswatini should be gathered. The Medicines and Related Substances Act of 2016 allows for the implementation of a pricing system for medicines in Eswatini. ${ }^{17}$ 


\section{Acknowledgements Competing interests}

The authors declare that they have no financial or personal relationships that may have inappropriately influenced them in writing this article.

\section{Authors' contributions}

F.S. and G.S. conceptualised the study. G.S. collected and analysed the data and drafted the initial article. F.S. supervised the study, validated the data and contributed to data analyses and the writing of the article. Both authors approved the final version of the article.

\section{Ethical consideration}

The research in this study has been approved by the Biomedical Research Ethics Committee of the University of KwaZulu-Natal and by the Kingdom of Eswatini Ministry of Health (BREC/00001237/2020).

\section{Funding information}

The authors received no financial support for the research, authorship and/or publication of this article.

\section{Data availability}

The data that support the findings of this study are available from the corresponding author, F.S., upon reasonable request.

\section{Disclaimer}

The views expressed in the submitted article are those of the authors own and not an official position of the institution or funder to which the authors are affiliated, and the publisher(s).

\section{References}

1. WHO. Global health expenditure database [homepage on the Internet]. c2014 [updated 2020 Nov 10; cited 2017 Mar 7]. Available from: http://apps.who.int/ nha/database

2. Nóbrega OT, Marques AR, Araújo ACG, et al. Retail prices of essential drugs in Brazil An international comparison. Rev Panam Salud Publica. 2007;22(2):118-123. https://doi.org/10.1590/S1020-49892007000700006

3. WHO. The world health report 2004: The world medicines' situation [homepage on the Internet]. Geneva: World Health Organization; c2004 [cited 2018 Dec 27]. Available from: http//www.who.int/medicinedocs/en/d/js6160e/9.html

4. Steinman MA, Sands LP, Covinsky KE. Self-restriction of medications due to cost in seniors without prescription coverage. J Gen Intern Med. 2001;16(12):793-799. seniors without prescription coverage. J Gen Intern
https://doi.org/10.1046/j.1525-1497.2001.10412.x

5. The world medicines situation 2011: Access to essential medicines as part of the right to health [homepage on the Internet]. Geneva: World Health Organization, c2011 [updated 2011 Jul 12; cited 2018 Apr 23]; p. 680, 689. Available from: http://apps.who.int/medicinedocs/documents/s18772en/s18772en.pdf

6. Kasonde L, Tordrup D, Naheed A, et al. Evaluating medicine prices, availability and affordability in Bangladesh using World Health Organization and Health Action International Methodology. BMC Health Serv Res. 2019;19(383):1-12. https:// doi.org/10.1186/s12913-019-4221-z

7. WHO/DAP. Global comparative pharmaceutical expenditures. Geneva: World Health Organization. Health economics and drugs, DAP Series No. 3 (in preparation)

8. Strengthening Pharmaceutical systems (SPS). Pharmaceuticals and the Public Interest: The Importance of Good Governance. submitted to the U.S. Agency for International Development by the SPS Program. Arlington, VA: Management Sciences for Health [cited 2021 Aug 16]. Available from: https://www.msh.org/ sites/default/files/sps_governance_pub_final_2011_0.pdf

9. Dylst $\mathrm{P}$, Simoen $\mathrm{S}$. Generic medicine pricing policies in Europe: Current status and impact. Pharmaceuticals. 2010;3(3):471-481. https://doi.org/10.3390/ph3030471
10. Barbar ZUD, Ibrahim MIM, Singh $\mathrm{H}$, et al. Evaluating drug prices, availability, affordability, and price components: Implications for access to drugs in Malaysia.
PLoS Med. 2007;4(3):466-475. https://doi.org/10.1371/journal.pmed.0040082

11. Danzon PM, Chao LW. Prices, competition and regulation in pharmaceuticals: A cross-national comparison. J Health Econ. 2000;19(2):159-195. https://doi. org/10.1016/S0167-6296(99)00039-9

12. Hassali MA, Alrasheedy AA, McLachlan A, et al. The experiences of implementing generic medicine policy in eight countries: A review and recommendations for a successful promotion of generic medicine use. Saudi Pharm J. 2014;22(6):491-503. https://doi.org/10.1016/j.jsps.2013.12.017

13. Chung C, Myers S. Do the poor pay more for food? An analysis of grocery store availability and food price disparities. J Consum Aff. 1999:33(2):276-296.https:// availability and food price disparities. J Consu
doi.org/10.1111/j.1745-6606.1999.tb00071.x

14. Gellad WF, Choudhry NK, Friedberg MW, et al. Drug prices at pharmacies: Are prices higher in poorer areas? Health Serv Res. 2009;44(2p1):606-617. https:// doi.org/10.1111/j.1475-6773.2008.00917.x

15. Madden JM, Ewen M, Laing RO, et al. Measuring medicine prices in Peru: Validation of key aspects of WHO/HAI survey methodology. Rev Panam Salud Publica. 2010;27(4):291-299. https://doi.org/10.1590/S1020-49892010000400008

16. Mhlanga BS, Suleman F. Price, availability and affordability of medicines. Afr J Prm Health Care Fam Med. 2014;6(1):a604. https://doi.org/10.4102/phcfm.v6i1.604

17. Swaziland Medicines and Related Substances Control Act 9 of 2016 [statute on the Internet]. c2016 [cited 2018 Mar 15]. Available from: http://www.gov.sz

18. Gelders S, Ewen M, Noguchi N, et al. Price, availability and affordability: An international comparison of chronic disease medicines. In: Background report prepared for the WHO planning meeting on the Global Initiative for treatment of chronic diseases held in Cairo in December 2005 [homepage on the Internet]. c2006 [cited 2018 Aug 15]. Available from: http://archives.who.int/medprices/ CHRONICANN.pdf

19. World Health Organization Regional Office for Africa. Service availability mapping report. Geneva; World Health Organization, Regional Office for Africa; 2010.

20. Kotwani A. Where are we now: Assessing the price, availability and affordability of essential medicines in Delhi as India plans free medicine for all. BMC Health Ser Res. 2013;13:285. https://doi.org/10.1186/1472-6963-13-285

21. International drug price indicator guide [homepage on the Internet]. Cambridge: Management Sciences for Health; c2011 [updated 2011 May 21; cited $2018 \mathrm{Feb}$ Kheder SI, Ali HM. Evaluating medicines' prices and availability in Sudan. Sudan Med Monit. 2014;9(1):19-30. https://doi.org/10.4103/1858-5000.144655

23. Fellowes M. From poverty, opportunity: Putting the market to work for lower income families. The Brookings Institution [serial online]. c2006 [cited 2017 Nov 02]. Available from: https://docs.google.com/viewerng/viewer?url=https:// community-wealth.org/sites/clone.community-wealth.org/files/downloads/ report-fellowes.pdf

24. Gray A, Suleman F. Pharmaceutical pricing in South Africa. In: Babar ZUD, editor Pharmaceutical prices in the 21st century. Adis: Cham, 2015; p. 251-265.

25. World Bank. World development report 1993: Investing in Health. New York, NY: Oxford University Press; 1993.

26. eSwatini (Swaziland) map and satellite image [homepage on the Internet] Geology.com; n.d. [cited 2021 Aug 16] Available from: https://geology.com/ world/swaziland-satellite-image.shtml

27. Knoema World Data Atlas [homepage on the Internet]. c2021 [cited 2021 Jun 19]. Available from: https://knoema.com/atlas/Eswatini/unemployment-rate

28. Exchange rates [homepage on the Internet]. c2021 [cited 2021 Jun 19]. Available from: https://www.exchangerates.org.uk/Swaziland-Lilageni-SZL-currency-table. htm

29. WHO/HAl. Measuring medicines prices, availability, affordability and price components [homepage on the Internet]. 2nd edition. c2008 [cited 2020 Aug 01].

30. WHO. WHO model list of essential medicines-21st list [homepage on the Internet]. c2019 [cited 2020 Sep 15]. Available from: https://www.who.int/publications/i/ item/WHOMVPEMPIAU2019.06

31. HAI. Collecting evidence on medicine prices and availability [homepage on the Internet]. c2008 [cited 2020 Sep 01]. Available from: https://haiweb.org/whatInternet]. c2008 [cited $2020 \mathrm{Sep} 01$ ]. Available from: https://haiweb.org/what-
we-do/price-availability-affordability/collecting-evidence-on-medicine-pricesavailability/

32. MSH. International medical products guide [homepage on the Internet]. c2020 [cited 2020 Sep 15]. Available from: https://mshpriceguide.org/en/home/

33. Medicines Price Registry [homepage on the Internet]. c2020 [cited 2020 Aug 15] Available from: https://medicineprices.org.za

34. Mediscor Pharmacy Benefit Management (PBM). Medicine reference price for South Africa [homepage on the Internet]. c2020 [cited 2020 Sep 1]. Available from: https://www.mediscor.co.za/

35. Guan X, Hu H, Man C, et al. A survey of availability, price and affordability of essential medicines from 2011 to 2016 in Chinese secondary and tertiary hospitals. Int J Equity Health. 2018;17:158. https://doi.org/10.1186/s12939-018-0870-5

36. Fang Y, Wagner AK, Yang $S$, et al. Access to affordable medicines after health reform: Evidence from two cross-sectional surveys in Shaanxi province, Western China. Lancet Glob. 2013;1(4):227-237. https://doi.org/10.1016/S2214-109X(13)70072-X

37. Faruqui $N$, Martiniuk $A$, Sharma A, et al. Evaluating access to essential medicines for treating childhood cancers: A Medicines availability, price and affordability study in New Delhi, India. BMJ Glob Health. 2019;4(2):1-11. https://doi. org/10.1136/bmjgh-2018-001379

38. Ongarora D, Karumbi J, Minnaard W, et al. Medicines prices, availability and affordability in private health facilities in low-Income settlements in Nairobi County, Kenya. Pharmacy. 2019;7(2):40. https://doi.org/10.3390/pharmacy7020040 


\section{Appendix 1}

TABLE 1-A1: Medicines' classification.

\begin{tabular}{|c|c|c|c|}
\hline $\begin{array}{l}\text { Medicine name (including strength and } \\
\text { dosage form) }\end{array}$ & $\begin{array}{l}\text { WHO/HAI } \\
\text { list }\end{array}$ & $\begin{array}{l}\text { Anti-infective/ } \\
\text { NCD }\end{array}$ & EML \\
\hline Acyclovir 200 mg cap/tab & $\mathrm{S}$ & Al & EML \\
\hline Amitriptyline 25 mg cap/tab & G & NCD & EML \\
\hline Amlodipine $5 \mathrm{mg}$ cap/tab & $\mathrm{S}$ & NCD & EML \\
\hline Amoxicillin 500 mg cap/tab & G & $\mathrm{Al}$ & EML \\
\hline $\begin{array}{l}\text { Amoxicillin + clavulanic acid } 125 \text { mg + } \\
31.25 \text { mg susp }\end{array}$ & $\mathrm{S}$ & Al & EML \\
\hline Anhydrous theophylline $200 \mathrm{mg}$ cap/tab & $\mathrm{S}$ & NCD & EML \\
\hline Artemether/lumefantrine $20 \mathrm{mg} / 120 \mathrm{mg}$ & S & $\mathrm{Al}$ & EML \\
\hline Atenolol 50 mg cap/tab & S & NCD & EML \\
\hline Atorvastatin $20 \mathrm{mg}$ cap/tab & $S$ & NCD & EML \\
\hline Azithromycin 500 mg cap/tab & S & $\mathrm{Al}$ & EML \\
\hline Beclomethasone $100 \mathrm{mcg} /$ dose $\mathrm{Inh}$ & S & NCD & EML \\
\hline Bisoprolol 5 mg cap/tab & G & NCD & EML \\
\hline Budesonide $0.5 \mathrm{mg} / \mathrm{mL}$ Neb susp & S & NCD & NEML \\
\hline Captopril 25 mg cap/tab & G & NCD & EML \\
\hline Carbamazepine $200 \mathrm{mg}$ cap/tab & S & NCD & EML \\
\hline Carvedilol $12.5 \mathrm{mg}$ cap/tab & $\mathrm{S}$ & NCD & EML \\
\hline Ceftriaxone injection $1 \mathrm{~g} / \mathrm{vial}$ & G & Al & EML \\
\hline Cetirizine $10 \mathrm{mg}$ cap/tab & S & NCD & EML \\
\hline Ciprofloxacin 500 mg cap/tab & G & Al & EML \\
\hline $\begin{array}{l}\text { Co-trimoxazole suspension } 8 \mathrm{mg}+40 \\
\mathrm{mg} / 5 \mathrm{~mL} \text { susp. }\end{array}$ & G & $\mathrm{Al}$ & EML \\
\hline Diazepam 5 mg cap/tab & G & NCD & EML \\
\hline Diclofenac $50 \mathrm{mg}$ cap/tab & G & NCD & EML \\
\hline Enalapril 20 mg cap/tab & $S$ & NCD & EML \\
\hline Fluoxetine $20 \mathrm{mg}$ cap/tab & $\mathrm{S}$ & NCD & EML \\
\hline Fluticasone/Salmeterol 25/250 mg Inh & $S$ & NCD & NEML \\
\hline Furosemide $40 \mathrm{mg}$ cap/tab & S & NCD & EML \\
\hline Glibenclamide 5 mg cap/tab & S & NCD & EML \\
\hline Gliclazide 80 mg cap/tab & S & NCD & EML \\
\hline Hydrochlorothiazide 25 mg cap/tab & $S$ & NCD & EML \\
\hline $\begin{array}{l}\text { Hydrochlorothiazide/losartan 12.5/50 mg } \\
\text { cap/tab }\end{array}$ & $\mathrm{S}$ & NCD & NEML \\
\hline Irbesartan $150 \mathrm{mg}$ cap/tab & S & NCD & EML \\
\hline Loratadine $10 \mathrm{mg}$ cap/tab & $\mathrm{S}$ & NCD & NEML \\
\hline Losartan 10 mg cap/tab & $\mathrm{S}$ & NCD & NEML \\
\hline Metformin 500 mg cap/tab & G & NCD & EML \\
\hline Methyldopa 250 mg cap/tab & $\mathrm{S}$ & NCD & EML \\
\hline Montelukast 5 mg cap/tab & $\mathrm{S}$ & NCD & NEML \\
\hline Nifedipine retard $20 \mathrm{mg}$ cap/tab & $\mathrm{S}$ & NCD & EML \\
\hline Omeprazole 20 mg cap/tab & G & NCD & EML \\
\hline Paracetamol suspension $24 \mathrm{mg} / \mathrm{mL}$ susp & G & NCD & EML \\
\hline Phenytoin 100 mg cap/tab & $\mathrm{S}$ & NCD & EML \\
\hline Propranolol $40 \mathrm{mg}$ cap/tab & $\mathrm{S}$ & NCD & EML \\
\hline Risperidone $2 \mathrm{mg}$ cap/tab & $\mathrm{S}$ & NCD & NEML \\
\hline Salbutamol inhaler $100 \mathrm{mcg} /$ dose & G & NCD & EML \\
\hline Salbutamol syrup $2 \mathrm{mg} / 5 \mathrm{~mL}$ & $\mathrm{~S}$ & NCD & EML \\
\hline Simvastatin 20 mg cap/tab & G & NCD & EML \\
\hline Sodium valproate $200 \mathrm{mg} \mathrm{cap} / \mathrm{tab}$ & S & NCD & EML \\
\hline Spironolactone 25 mg cap/tab & S & NCD & EML \\
\hline Tamsulosin 0.4 mg cap/tab & $S$ & NCD & NEML \\
\hline
\end{tabular}

$\mathrm{mg}$, milligrams per dosage form; cap/tab, capsules or tablets as a dosage form; $\mathrm{mcg} / \mathrm{dose}$ micrograms per dose of medicine; S, supplementary list; G, Global Core List; NCD, noncommunicable disease; $\mathrm{Al}$, anti-infectives; EML, essential medicines list; NEML, not on essential medicines list; Inh, inhaler; Neb susp, Nebulising suspension; WHO/HAl, World Health Organization/Health Action International. 